\title{
Morphometric Study of Pinna in Relation to Age in Uttar Pradesh Population
}

\author{
Vidit Pratap Dixit ${ }^{1}$, Pratishtha Potdar ${ }^{2 \star}$, Jagmohan Singh Dhakar ${ }^{3}$ \\ ${ }^{1}$ Senior Demonstrator, Department of Anatomy, Rama Medical College Hospital and Research Centre, Hapur, U.P, India \\ ${ }^{2}$ Associate Professor, Department of Anatomy, Santosh Medical College, Ghaziabad, U.P, India \\ ${ }^{3}$ Statistician cum Assistant Professor, Department of Community Medicine, Santosh Medical College, Ghaziabad, U.P, \\ India
}

*Address for Correspondence: Dr. Pratishtha Potdar, Associate Professor, Department of Anatomy, Santosh Medical College, Ghaziabad, India

E-mail: drpratishthagupta@gmail.com

Received: 11 Apr 2019/ Revised: 09 Jul 2019/ Accepted: 27 Aug 2019

\begin{abstract}
Background: Morphometric dimensions of ear plays a very important role in plastic surgery and prosthetics. This study aimed to determine different morphometric parameters of both ear and to provide information regarding age related changes.

Methods: A study was conducted on 167 subjects including both males and females. The ear was measured using vernier caliper with an accuracy of 0.001 and recorded in millimeters $(\mathrm{mm})$ in a data sheet. The size of pinna and the lobule were measured on both right and left side and were correlated with age of the individual. Readings were statistically analyzed in order to determine the relationship between the size of the pinna and the age of the individual.

Results: In our study of age 18-30 ear length was $6.15 \mathrm{~cm}$, lobule length and width was $1.87 \mathrm{~cm}$ and $1.99 \mathrm{~cm}$ and in age 31-40 ear length was $6.32 \mathrm{~mm}$, lobular length and width was $1.95 \mathrm{~cm}$ and $2.01 \mathrm{~cm}$ and in age 41-50 yrs ear length was $6.415 \mathrm{~cm}$, lobular length and width was $1.98 \mathrm{~cm}$ and $2.06 \mathrm{~cm}$. This shows that in our study ear length were increasing significantly with age and similarly Rt and Lt lobular length and Lt lobular width were also increasing significantly with the age. There was no significant difference between the size of the right and left pinna.

Conclusion: The present study shows that the expansion of auricle with age was related to structural change in auricular cartilage. The ear morphometry also helps in predicting ear anomalies and to reproduce anatomically corrected ear during its reconstruction.
\end{abstract}

Key-words: Ear auricle, Ear length, Ear lobule, Ear width, Morphopometry

\section{INTRODUCTION}

Human ear is a complex, curved inter wined substructure as compared to rest of human body, its shape is framed in such a way to allow spatial localization of sounds ${ }^{[1]}$. Human ear convey sign of age and gender that are ill defined ${ }^{[2]}$. The anatomical structures of the external ear are utilized for personal identification of living subjects in relation to criminal activity.

How to cite this article

Dixit V, Potdar P, Dhakar JS. Morphometric Study of Pinna in Relation to Age in Uttar Pradesh Population. SSR Inst. Int. J. Life Sci., 2019; 5(5): 2379-2386.

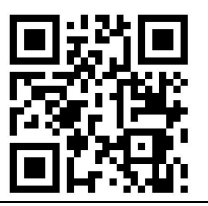

There have been claims in recent years that the external ear may be utilized for personal identification of both living and deceased individuals ${ }^{[3]}$. So knowledge about normal auricular dimensions is important in diagnosis of congenital malformation syndromes and acquired deformities. The size of human auricle continues to enlarge until advanced age and it is well known that this structural changes of auricular cartilage is associated with morphological age changes of elastic fibers, which was one of important cause of expansion of auricle even after adulthood ${ }^{[4,5]}$. Many studies have been done on expansion of ear auricle by measuring the size of auricle but mechanism of expansion is still not clear ${ }^{[6]}$. Although various studies on morphological changes of auricular cartilage with age changes and few on fine structure of auricular cartilage have been reported but 
no literature are available on ultra structural age changes in human auricular cartilage ${ }^{[7,8]}$. The human ear is divided into external, middle and internal parts. The pinna and the external acoustic meatus form the external ear. The lateral surface of the pinna is irregularly concave, faces slightly forward and displays numerous eminences and depressions (Fig. 1). It was of great interest that elastic fibers in auricular cartilage undergoes structural changes with age similar to dermis of skin as this elastic fibers play a fine role in extension of auricular length after puberty ${ }^{[9,10]}$. In the present study, we measured various parameters of human and also determined the relationship between ear sizes with age of the adult North Indian population.

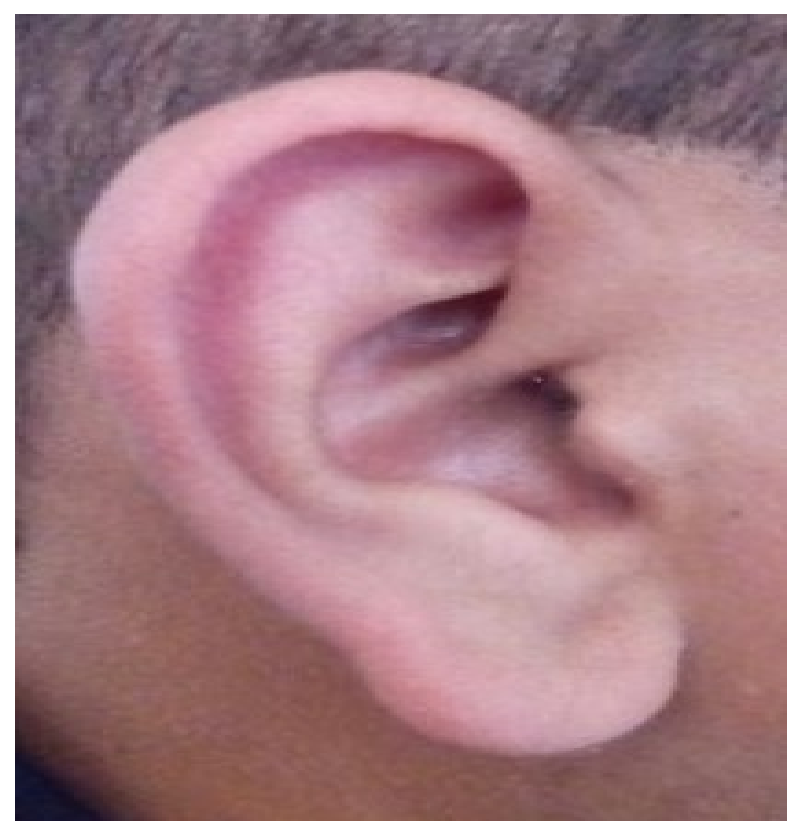

Fig. 1: External features of ear

\section{MATERIALS AND METHODS}

The present study was carried out on the North Indian population, in the age group of 18-60 years including 167 Males and 33 Females. Written consent was obtained from each participant in a prescribed format. Each participant was informed about the nature of the study before obtaining the consent. Healthy individuals in an age group of 18-60 years, without any deformity or abnormality and willingness to participate in the study were included in this study. Age groups below 18 and above 65 years of age, having any type of physical deformity or ear injury were excluded. The subjects were divided into four groups according to their age at intervals of 5 years.
The measurements related to total ear length and ear width and lobule length and width were taken with a digital Vernier Caliper as shown in Fig. 2.

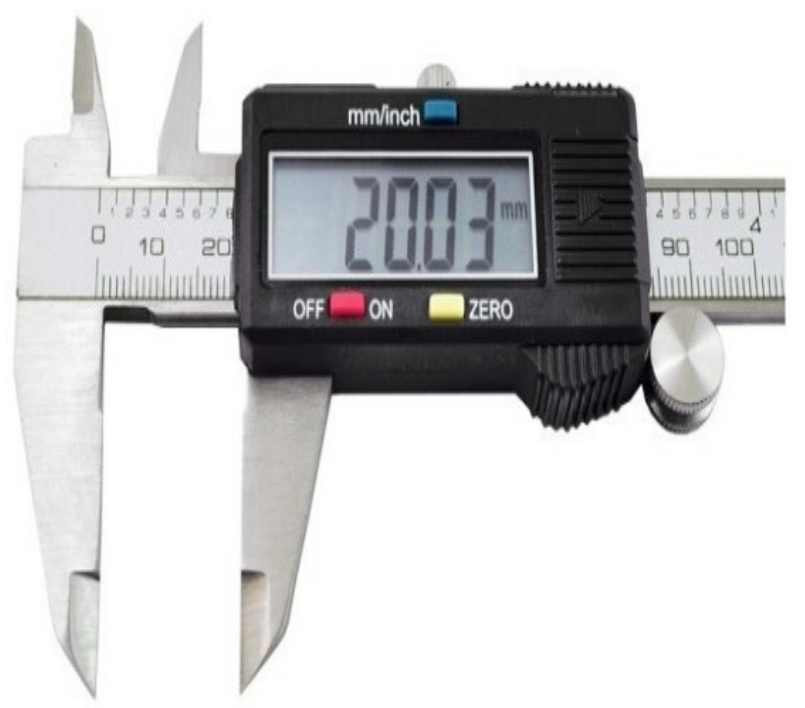

Fig. 2: Digital Vernier Caliper

The observations were made according to the methods of Eboh ${ }^{[11]}$. Each subject was made to sit in a natural head position in a chair with a backrest and positioned in such a way so that the eyes of the subject looks straight forward with the lower border of the eye sockets in the same horizontal plane as the external auditory meatus.

Total ear length was measured as the distance from the most superior point of the helix $(A)$ to the most inferior point of the ear lobule (B). Total ear width was determined by measuring along the broadest part of the pinna from the (D) to (C) as shown in Fig. 3.

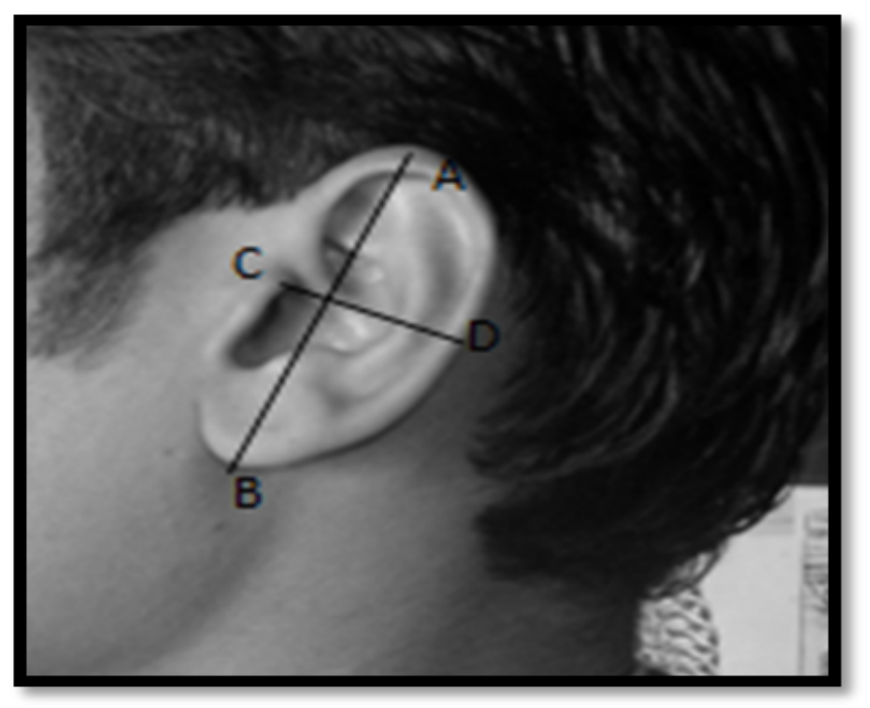

Fig. 3: Left pinna showing the total length $A$ to $B$ and ear width from $C$ to $D$ 
Total lobule length was taken as the distance from the tip of anti-tragus $(E)$ to most inferior point of the lobule (B) and the total lobule width was measured as the horizontal distance of the lobule at the midpoint of the lobule length (EB) as shown in Fig. 4.

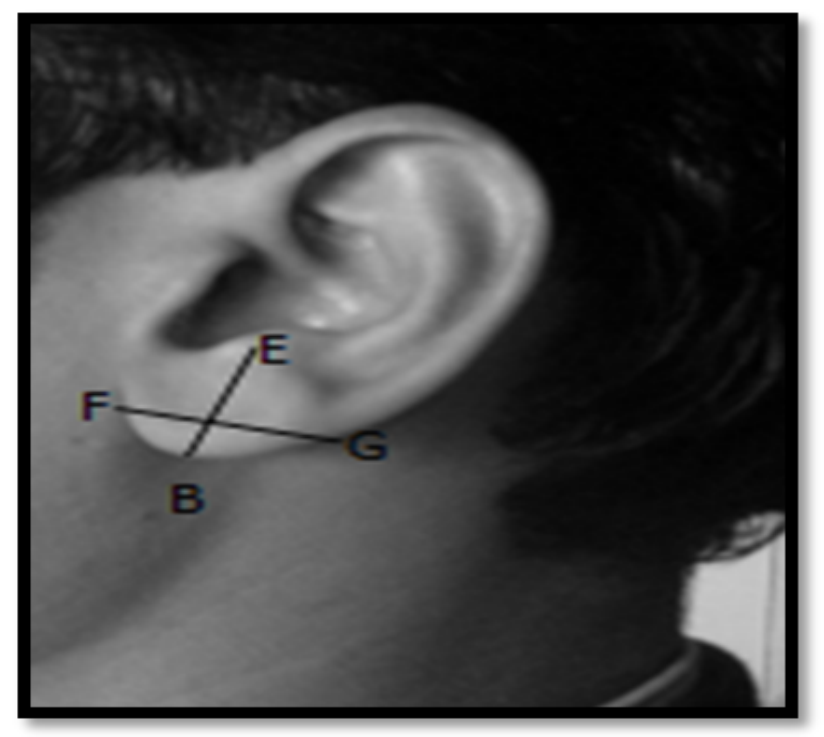

Fig. 4: Left pinna lobule length $E$ to $B$ and lobule width from $F$ to $G$
Statistical Analysis- All the four parameters of right and left ears were taken by digital venier caliper with an accuracy of 0.001 and recorded in millimeters $(\mathrm{mm})$ in a data sheet. All subjects were divided into four groups according to their age. The Pearson correlation is used to establish the relationship between the size of the pinna and the age of the individual and the data was analyzed using SPSS version $23, p<0.05$ was significant.

\section{RESULTS}

The pinna of 167 subjects were measured in the age group of 18-57 years, which show that there was a gradual increase in length of the pinna with advancing age till $40-50$ yrs and thereafter it is non-significant. The results have been summarized as below.

Table 1 shows that there was a gradual increase in the length of the pinna with advancing age till 40-50 yrs and thereafter it was non-significant.

Table 1: Morphometric measurements of pinna in relation to age

\begin{tabular}{|c|c|c|c|c|c|c|}
\hline \multirow{2}{*}{ Groups } & \multirow{2}{*}{ Age (Yrs) } & \multirow{2}{*}{$\begin{array}{l}\text { Number of } \\
\text { subjects }\end{array}$} & \multicolumn{2}{|c|}{ Mean pinna length (mm) } & \multicolumn{2}{|c|}{ Mean ear width (mm) } \\
\hline & & & REL & LEL & REW & LEW \\
\hline A & $18-30$ & 114 & $61.58 \pm 3.86$ & $61.47 \pm 3.8$ & $24.41 \pm 2.51$ & $24.53 \pm 2.4$ \\
\hline B & $31-40$ & 54 & $63.23 \pm 4.68$ & $63.18 \pm 4.45$ & $24.72 \pm 2.36$ & $24.71 \pm 2.43$ \\
\hline C & $41-50$ & 24 & $64.15 \pm 4.23$ & $64.02 \pm 4.31$ & $24.63 \pm 2.25$ & $24.6 \pm 2.60$ \\
\hline D & $51-60$ & 8 & $64.36 \pm 2.59$ & $64.36 \pm 2.59$ & $25.7 \pm 1.75$ & $25.7 \pm 1.75$ \\
\hline
\end{tabular}

REL- Right ear length; LEL- Left ear length; REW- Right ear width; LEW- Left ear width P-value (>0.005) $=$ Non-significant

Table 2 shows that there was a gradual increase in length and width of lobule from 18.79 and $19.57 \mathrm{~mm}$ at the age of $18-30$ yrs to $21.24 \mathrm{~mm}$ and $21.03 \mathrm{~mm}$ at the age of 51-60 with advancing age. 


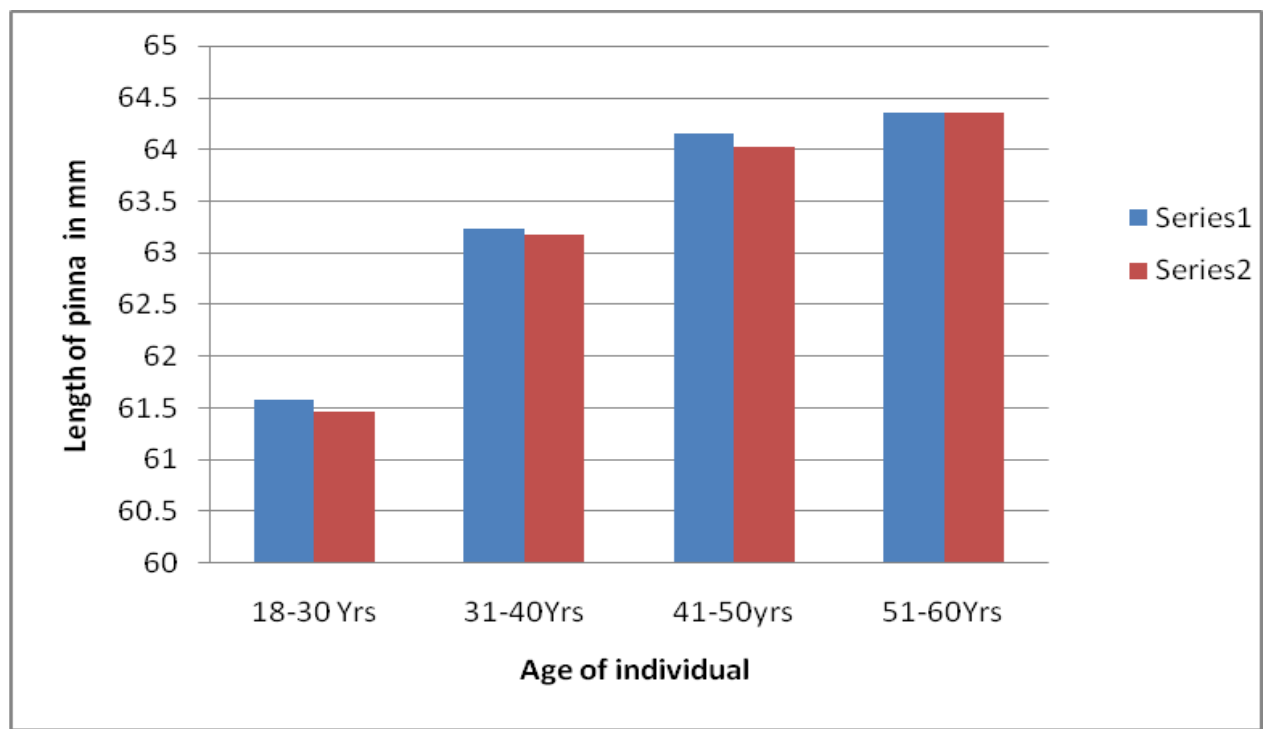

Fig. 5a: Relation between the lengths of pinna with age of individual

Series 1- Average length of right ear, Series 2- Average length left ear

Table 2: Morphometric measurements of lobule in relation to age

\begin{tabular}{ccccccc}
\hline \multirow{2}{*}{ Groups } & Age (Yrs) & $\begin{array}{c}\text { Number of } \\
\text { subjects }\end{array}$ & & \multicolumn{2}{c}{ Mean lobule length (mm) } & \multicolumn{2}{c}{ Mean lobule width (mm) } \\
\cline { 4 - 7 } & & & RLL & LLL & RLW & LLW \\
\hline A & $18-30$ & 114 & $18.79 \pm 2.86$ & $18.73 \pm 2.83$ & $19.98 \pm 2.58$ & $19.57 \pm 2.1$ \\
B & $31-40$ & 54 & $19.53 \pm 2.31$ & $19.43 \pm 2.34$ & $20.18 \pm 2.58$ & $20.17 \pm 2.64$ \\
C & $41-50$ & 24 & $19.84 \pm 2.53$ & $20.62 \pm 2.56$ & $20.61 \pm 2.55$ & $20.23 \pm 2.4$ \\
D & $51-60$ & 8 & $20.99 \pm 3.45$ & $21.24 \pm 3.46$ & $21.03 \pm 1.92$ & $21.03 \pm 1.92$ \\
\hline
\end{tabular}

RLL-Right lobule length, LLL- LEFT lobule width, RLW- Right lobule width, LLW Left lobule width

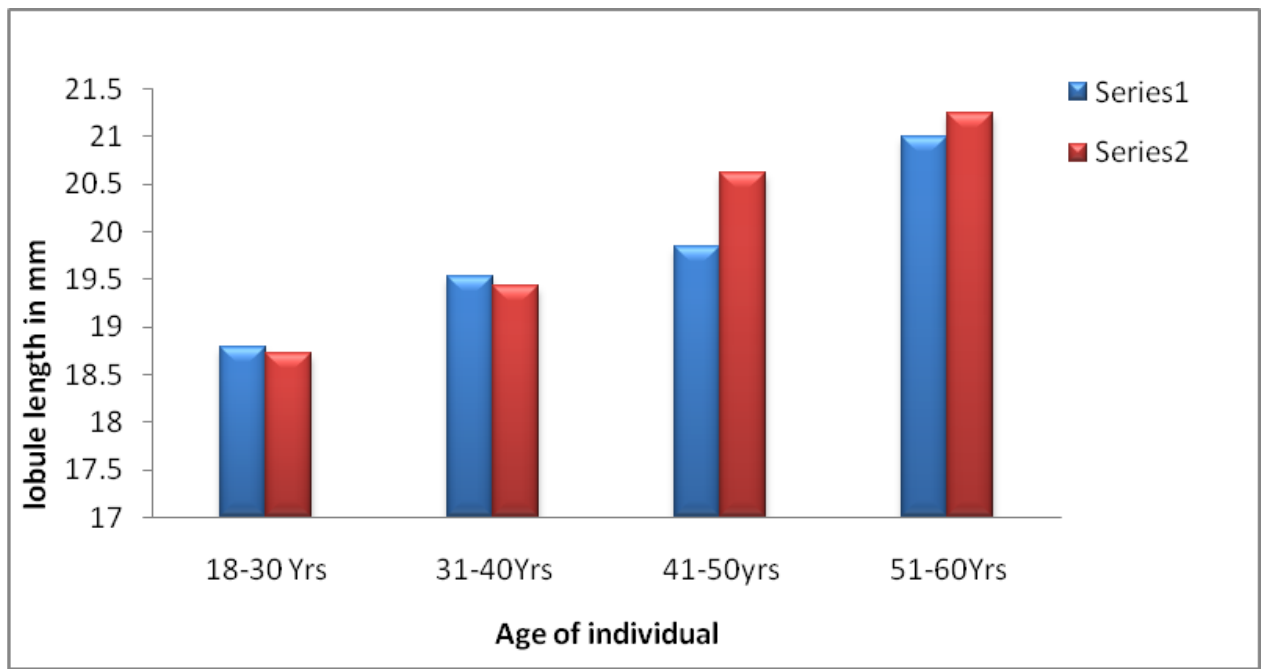

Fig. 5 b: Relation between the lengths of lobule with age of individual Series 1- Mean length of right lobule, Series 2- Mean length of left lobule 
Table 3 shows that the right and left pinna length were the same. Table 3 shows that right and left ear length was 61.58 and $61.47 \mathrm{~mm}$ at the age of $18-30 \mathrm{yrs}, 64.36$ $\mathrm{mm}$ and $64.36 \mathrm{~mm}$ at the age of $51-60$. This shows that there was a non-significant difference between right and left pinna length.

Table 3: Correlation between right and left pinna in relation to age

\begin{tabular}{cccccc}
\hline \multirow{2}{*}{ Groups } & Age $($ Yrs $)$ & $\begin{array}{c}\text { Number of } \\
\text { subjects }\end{array}$ & \multicolumn{2}{c}{ Mean pinna length $(\mathbf{m m})$} & \multirow{2}{*}{ P-value } \\
\cline { 4 - 5 } & & 114 & $61.58 \pm 3.86$ & $61.47 \pm 3.80$ & 0.82 \\
A & $18-30$ & 54 & $63.23 \pm 4.68$ & $63.18 \pm 4.45$ & 0.95 \\
B & $31-40$ & 24 & $64.15 \pm 4.23$ & $64.02 \pm 4.31$ & 0.91 \\
C & $41-50$ & 8 & $64.36 \pm 2.59$ & $64.36 \pm 2.59$ & 1.00 \\
\hline
\end{tabular}

P-value $(>0.005)=$ Non-significant

Table 4 shows that right and left ear width was 24.41 and $24.53 \mathrm{~mm}$ at the age of $18-30 \mathrm{yrs}, 25.7 \mathrm{~mm}$ and $25.7 \mathrm{~mm}$ at the age of $51-60$. This shows that there was nonsignificant difference between right and left pinna width.

Table 4: Correlation of right and left pinna width in relation to age

\begin{tabular}{|c|c|c|c|c|c|}
\hline \multirow{2}{*}{ Groups } & \multirow{2}{*}{ Age (Yrs) } & \multirow{2}{*}{$\begin{array}{l}\text { Number of } \\
\text { subjects }\end{array}$} & \multicolumn{2}{|c|}{ Mean ear width (mm) } & \multirow{2}{*}{ P-value } \\
\hline & & & REW & LEW & \\
\hline A & $18-30$ & 114 & $24.41 \pm 2.51$ & $24.53 \pm 2.4$ & 0.71 \\
\hline B & $31-40$ & 54 & $24.72 \pm 2.36$ & $24.71 \pm 2.43$ & 0.98 \\
\hline C & $41-50$ & 24 & $24.63 \pm 2.25$ & $24.6 \pm 2.6$ & 0.96 \\
\hline D & $51-60$ & 8 & $25.7 \pm 1.75$ & $25.7 \pm 1.75$ & 1.00 \\
\hline
\end{tabular}

P-value (>0.005)= Non-significant

Table 5 shows that right and left lobular length was 18.79 and $18.73 \mathrm{~mm}$ at the age of $18-30 \mathrm{yrs}, 20.99 \mathrm{~mm}$ and $21.24 \mathrm{~mm}$ at the age of 51-60. This shows P-value
$(>0.005)$, which means there was non-significant difference between right and left lobular length.

Table 5: Correlation of right and left lobule length in relation to age

\begin{tabular}{cccccc}
\hline \multirow{2}{*}{ Groups } & Age (Yrs) & $\begin{array}{c}\text { Number of } \\
\text { subjects }\end{array}$ & \multicolumn{2}{c}{ Mean lobule width (mm) } & \multirow{2}{*}{ P- value } \\
\cline { 4 - 5 } & & 114 & $18.79 \pm 2.86$ & $18.73 \pm 2.83$ & 0.83 \\
A & $18-30$ & & & & \\
& $31-40$ & 54 & $19.53 \pm 2.31$ & $19.43 \pm 2.34$ & 0.82
\end{tabular}




$\begin{array}{lrrrrr}\text { C } & 41-50 & 24 & 19.84 \pm 2.53 & 20.62 \pm 2.56 & 0.29 \\ \text { D } & 51-60 & 8 & 20.99 \pm 3.45 & 21.24 \pm 3.46 & 0.88\end{array}$

P-value (>0.005) $=$ Non-significant

Table 6 shows that right and left lobule width were 19.98 $\mathrm{mm}$ and $19.57 \mathrm{~mm}$ at the age of $18-30 \mathrm{yrs}$ which was increasing to $21.03 \mathrm{~mm}$ and $21.03 \mathrm{~mm}$ at the age of 51$60 \mathrm{yrs}$, this shows that right and left lobular width have the non-significant difference.

Table 6: Correlation of right and left lobule width in relation to age

\begin{tabular}{cccccc}
\hline \multirow{2}{*}{ Group } & Age (Yrs) & $\begin{array}{c}\text { Number of } \\
\text { subjects }\end{array}$ & \multicolumn{2}{c}{ Mean lobule width in $\mathbf{~ m m}$} & P- value \\
\cline { 4 - 5 } & & 114 & $19.98 \pm 2.58$ & Left & \\
\hline A & $18-30$ & 54 & $20.18 \pm 2.58$ & $19.57 \pm 2.1$ & 0.18 \\
B & $31-40$ & 24 & $20.61 \pm 2.55$ & $20.17 \pm 2.64$ & 0.98 \\
C & $41-50$ & 8 & $21.03 \pm 1.92$ & $20.23 \pm 2.4$ & 0.65 \\
D & $51-60$ & & & $21.03 \pm 1.92$ & 1.00 \\
\hline
\end{tabular}

Table 7 shows that the right ear length was increased significantly with age, similarly right and left lobular length and left lobular width were increasing significantly with the age as $p$-value was $<0.001$.

Table 7: Correlation of ear dimensions with age

\begin{tabular}{|c|c|c|c|c|c|c|c|c|}
\hline & \multicolumn{2}{|c|}{ Total ear length (mm) } & \multicolumn{2}{|c|}{ Total ear width (mm) } & \multicolumn{2}{|c|}{$\begin{array}{l}\text { Lobular length } \\
\qquad(\mathrm{mm})\end{array}$} & \multicolumn{2}{|c|}{ Lobular width (mm) } \\
\hline & Right & Left & Right & Left & Right & Left & Right & Left \\
\hline $\begin{array}{c}\text { Correlation } \\
\text { (r) }\end{array}$ & 0.288 & 0.017 & 0.088 & 0.082 & 0.266 & 0.283 & 0.130 & 0.109 \\
\hline p-value & 0.001 & 0.811 & 0.214 & 0.248 & 0.001 & 0.001 & 0.067 & 0.124 \\
\hline
\end{tabular}

\section{DISCUSSION}

Morphometric data provides a valuable source of information to ergonomists and designers, who attempted to consider a range of body sizes and abilities in the design of occupational environments and products. Itoh et al. ${ }^{[12]}$ studied the morphological age changes in adult human auricular cartilage in 1958 subjects and found that the histological changes of the auricular cartilage containing elastic fibers may be one of the reasons of ear length increases with age. Sharma et al. ${ }^{[13]}$ in his morphometric study of ear lobule in 260 northwest Indians between the age of 1 to 80 years observed that maximum length of the lobule increased appreciably between 6-15 years and 41-80 years similarly our study also shows that ear length and lobule length increases from age 18 yrs to 60 yrs as $61.58 \mathrm{~mm}$ on right ear and 61.47 on left ear at age of 18-30, which was increased to $64.36 \mathrm{~mm}$ on right and $64.36 \mathrm{~mm}$ on left ear at the age of 51-60 yrs. 
Liu ${ }^{[14]}$ incorporated anthropometric measurement on 200 hundred subjects with age 20-59 year, found that pinna length was $52.8 \pm 8.7 \mathrm{~mm}$ in 20 year age group, in 30 year age group pinna length was $56.3 \pm 5.8 \mathrm{~mm}$ and 40 year age group pinna length was $56.6 \pm 6.90 \mathrm{~mm}$, and in 50 year age group pinna length was $59.1 \pm 7.1 \mathrm{~mm}$ showing increase in pinna length with age. Similarly in our study pinna length was $61.58 \pm 3.86 \mathrm{~mm}$ at the age 18-30 yrs, $63.23 \pm 4.68 \mathrm{~mm}$ at the age $31-40 \mathrm{yrs}$, $64.15 \pm 4.32$ at the age $41-50 \mathrm{yrs}, 64.36 \pm 2.59 \mathrm{~mm}$ at the age 51-60 yrs showing increase in pinna length with age. Ekanem et al. ${ }^{[15]}$ did an anthropometric study of pinna on 217 adult Nigerians in Maiduguri between 18 to 65 years and the subjects were divided into 11 groups showed that the total ear length and total lobular length are increasing significantly as same as our study.

Sullivan et al. ${ }^{[16]}$ shown in his morphometric study of the external ear on 123 volunteers, 89 women and 34 men with 18 to 65 years age. They divided all subjects into 3 groups with 15 year age intervals and measured total ear length, lobule length and width. In a group of 15-30 years total ear length was $6.17 \mathrm{~cm}$ and lobule length and width $1.78 \mathrm{~cm}$ and $2.10 \mathrm{~cm}$ similarly in our study of age 18-30 ear length was $6.15 \mathrm{~cm}$, lobule length and width was $1.87 \mathrm{~cm}$ and $1.99 \mathrm{~cm}$. In 31-45 year age group, total ear length was $6.27 \mathrm{~cm}$, lobule length and width was $1.85,1.96 \mathrm{~cm}$ respectively, similarly in our study of age 31-40 ear length was $6.32 \mathrm{~mm}$, lobular length and width was $1.95 \mathrm{~cm}$ and $2.01 \mathrm{~cm}$. In 46-60 year age group total ear length was $6.45 \mathrm{~cm}$, lobule length and width was, $1.99 \mathrm{~cm}, 1.97 \mathrm{~cm}$ similarly in our study of age 41-50 yrs ear length is $6.415 \mathrm{~cm}$, lobular length and width was 1.98 $\mathrm{cm}$ was $2.06 \mathrm{~cm}$ this shows that ear length and lobular length are increasing with age. Oludiran and Omotoso ${ }^{[17]}$ shown in the adult of 18 to 30 year, total ear length of the left and the right side were $58.6 \pm 5.2 \mathrm{~mm}, 58.5 \pm 4.9$ $\mathrm{mm}$ and width $33.3 \pm 4.8 \mathrm{~mm}, 34.0 \pm 4.9 \mathrm{~mm}$. Total ear lobular length of left and right side was $15.8 \pm 3.3 \mathrm{~mm}$, $15.9 \pm 3.6 \mathrm{~mm}$ and total ear lobule width $17.2 \pm 4.0 \mathrm{~mm}$, $17.2 \pm 4.2 \mathrm{~mm}$. There were no significant differences in ear parameters of right and left side ear similar to our study. Taura et al. ${ }^{[18]}$ reported that the correlation is higher with height in right ear width, while in our study ear length and lobular length and width were increased significantly with the age. In our study we also explained that increase in lobular length is not due to weight effects of earing but due to ageing process. Deopa et al.
[19] observed that there were differences in anthropometric data of people from different regions in India similarly Jung ${ }^{[20]}$ also surveyed the dimensions and characteristic of Korean ears and found that age, gender and different ethnic population were determinants of ear dimensions. According to Kalra and Kalra ${ }^{[21]}$, the breadth of ear lobule increased up to the age of $15 \mathrm{yrs}$ nearest to 0-1 $\mathrm{mm}$ and almost static between 16-40 yrs increases again from 41 yrs onwards while in our study ear length and ear width were increasing significantly.

When we compare our study with those of others we find there was a difference in the value of ear measurement and these discrepancies could be result of various factors such as race, genetic variable, individual constitution, environment, age and human error.

\section{CONCLUSIONS}

In the present study, we confirmed that the auricular size increased significantly after reaching adulthood until advanced age by morphometric parameters of the ear. It thus appeared that elastic fibers and components of the extracellular matrix in the auricular cartilage changed structurally with ageing. Therefore, it is concluded that further study was required to provide a different formula for different sex with large population size. With these appropriate normative data, it is hoped that better and objective reference material would be provided for the aesthetic plastic surgeon, forensic purpose, in particular, those engaged in ear rejuvenation in the country.

\section{CONTRIBUTION OF AUTHORS}

Research concept- Dr. Pratishtha Potdar

Research design- Dr. Vidit Pratap Dixit

Supervision- Dr. Pratishtha Potdar

Materials- Dr. Vidit Pratap Dixit

Data collection- Dr. Vidit Pratap Dixit

Data analysis and Interpretation- Dr. Jagmohan Singh

Dhakar

Literature search- Dr. Jagmohan Singh Dhakar

Writing article- Dr. Pratishtha Potdar

Critical review- Dr. Jagmohan Singh Dhakar

Article editing- Dr. Pratishtha Potdar

Final approval- Dr. Pratishtha Potdar

\section{REFERENCES}

[1] Bozkar MG, Karakas P, Yavuz M, Dere F. Morphometric of External Ear in our Adult 
Population. Aesthetic Plast. Surg., 2006; 30(8): 81-85.

[2] Brucker JM, Patel J, Sullivan PK. A morphometric study of the external ear: age- sex related difference. Plast. Reconstr. Surg., 2003; 112(2): 647-53.

[3] Abbas A, Rutty GN. Ear piercing affects ear prints, The role of ear piercing in human identification. J. Forensic Sci., 2005; 50(2): 386-92.

[4] Ito I, Imada M, Ikeda M, Sueno K, Arikuni T, et al. A morphological study of age changes in adult human auricular cartilage with special emphasis on elastic fibers. Larygoscope, 2001; 111: 881-86.

[5] Fox TF, Hon HK, Wong E, Chang A. Auricular anthropometry of Hongkong Chinese babies. Clin. Ortho. Dont. Res., 2004; 7: 10-14.

[6] Feathers DJ, Paquet V, Drury CG. Measurement consistency and three-dimensional electro mechanical anthropometry. Int. J. Industrial Ergonomics, 2004; 33: 181-90.

[7] Coward TJ, Scott B, Watson RM, Richard R. Laser scanning of ear identifying the shape and position in subjects with normal facial symmetry. Int. J. Oral Maxillofac. Surg., 2000; 29: 18-23.

[8] Kostovic-Knezevic L, Bradamante Z, Svajger A. Ultrastructure of elastic cartilage in rat external ear. Cell Tissue Res., 2001; 218(1): 149-60.

[9] De carvalho Filho ET, De Souzo RR, et al. Age related changes in elastic fibers of human heart. Gerentology, 2003; 42; 211-17.

[10]Brucker MJ, Patel J, Sullivan PK. A morphometric study of the external ear; Age and sex related differences. Plast. Reconstr. Surg., 2003; 112(2); 64752.

[11]Eboh DEO. Morphological changes of the human pinna in relation to age and gender of Urhobo people in Southern Nigeria. J. Exp. Clin. Anat., 2013; 12: 6874.
[12]Itoh M, Ikeda, K Sueno, et al. Anthropometric study on normal human auricle in Japan. 2001; 104(2): 165-74. doi: 10.3950/jibiinkoka.104.165.

[13]Sharma A, Sidhu NK, Sharma MK, et al. Morphometric study of ear lobule in northwest Indian male subjects. Anat. Sci. Int., 2007; 82(2): 98104. doi: 10.1111/j.1447-073X.2007.00166.x.

[14]Liu BS. Incorporating anthropometry into design of ear-related products. Appl. Ergon. 2008; 39(1):11521.

[15]Ekanem AU, Garba SH, et al. Anthropometric study of the pinna (auricle) among adult Nigerian resident in Maiduguri metropolis. J. Med. Sci., 2010; 176-80. doi: 10.3923/jms.2010.176.180.

[16]Sullivan PK, Micheal J, Patel J. A Morphometric study of the external ear: age and sex related differences. J. Plastic Surg., 2010; 401-06.

[17]Oludiran OO, Omotoso DR. A morphometric study of the external ears at Benin City. Nig. J. Plast. Surg., 2012; 8(1): 1-5.

[18]Taura MG, Adamu LH, Gudaji A, Modibbo MH. High Prediction from external ear morphometry; A pilot study. Int. J. Res. Heal. Sci., 2016; 4(1): 15-19.

[19]Deopa D, Thakkar HK, Prakash C, Nirajan R, Barua MP. Anthropometric measurement of external ear of medical students in Uttarakhand Region. J. Anatomical Society India, 62, 2013; 79-83.

[20]Jung $\mathrm{SH}$. Surveying the dimensions and characteristics of Korean ears for the ergonomics design of ear-related products. Int. J. Ind. Ergon., 2003; 31: 361-73.

[21] Kalra D, Kalra A. Anthrometric measurement of external ear. Int. J. Enhanced Res. Med. Dental care, 2015; 2(3): 10-16. 